Int. J. Electrochem. Sci., 12 (2017) 2389 - 2399

\title{
Fabrication of Electrochemical Immunosensor for Cardiac Biomarker Troponin I Determination and Its Potential for Acute Myocardial Infarction Diagnosis
}

\author{
Zhibo $\mathrm{Li}^{1}, \mathrm{Ke} \mathrm{Ma}^{3}$, Zhihua Cheng ${ }^{3}, \mathrm{Cui} \mathrm{Yan}^{1 *}$ and Guifeng Liu ${ }^{2 *}$ \\ ${ }^{1}$ The Second Hospital of Jilin University, 218 Ziqiang St, Nanguan Qu, Changchun Shi, Jilin, 130041, \\ P.R. China \\ ${ }^{2}$ The Third Hospital of Jilin University, Jilin, 130041, P.R. China \\ ${ }^{3}$ The First Hospital of Jilin University, Jilin, 130041, P.R. China \\ *E-mail: hqhy32302@sina.com; jlfsliuguifeng@163.com
}

doi: $10.20964 / 2017.03 .12$

Received: 28 November 2016 / Accepted: 4 January 2017 / Published: 12 February 2017

The detection of cardiac troponin I (cTnl) at extremely low concentration was highly demanded since it was identified as a principal diagnostic marker for acute myocardial infarction. In this study, a composite of poly(diallyldimethylammonium chloride) (PDDA) and reduced graphene oxide (RGO) was successfully prepared and then employed for constructing immunosensors. The proposed immunosensor demonstrated excellent performance for the determination of cTnl with low detection limit $(0.024 \mathrm{ng} / \mathrm{mL})$ and wide linear response range $(0.1-10 \mathrm{ng} / \mathrm{mL})$. The proposed immunosensor has demonstrated promising potential in diagnose of acute myocardial infarction owing to the great deal of advantages such as remarkable sensitivity and reproducibility.

Keywords: Immunosensor; Cardiac biomarker; Troponin I; Graphene; Acute myocardial infarction

\section{$\underline{\text { FULL TEXT }}$}

(C) 2017 The Authors. Published by ESG (www.electrochemsci.org). This article is an open access article distributed under the terms and conditions of the Creative Commons Attribution license (http://creativecommons.org/licenses/by/4.0/). 